\title{
PENGETAHUAN DAN SIKAP REMAJA PUTRI TENTANG GANGGUAN MENSTRUASI DI KELAS XII SMAN 02 PEKANBARU
}

\author{
RUMMY ISLAMI ZALNI \\ STIKes Tengku Maharatu \\ Rummy.i.zalni@gmail.com
}

\begin{abstract}
Menstrual disorders are more common in adolescents (16-19 years old), in the form of irregular menstruation, fewer menstruation and very much, menstrual pain and menstruation more often. The purpose of research to know the description of knowledge and attitude of young women about menstrual disorders in class XII SMAN 02 Pekanbaru. The research design is quantitative with descriptive method with cross sectional approach. The research was conducted on July 26 to August 16, 2013 at SMAN 02 Pekanbaru class VII in 2013. The population in this study is all students of class XII SMAN 02 Pekanbaru in 2013. Population in this research is all The students of grade XII SMAN 02 Pekanbaru in 2013 amounted to 149 people and the sample was taken by simple random sampling which was 60 people. Analysis of knowledge data used is univariate data analysis and attitude analysis using Likert scale. The result of the research shows that majority of respondents' knowledge is 43 people (71.67\%) and the majority of female attitudes about menstruation disorder in SMAN 02 Pekanbaru is negative 33 people (55\%). It is expected that the results of this study can be used as information where menstrual disorders are important things to know. So that young women can overcome if the existence of menstrual disorders.
\end{abstract}

Keywords: Young Women, Menstrual Disorders

\begin{abstract}
Abstrak: Gangguan haid yang lebih sering terjadi pada remaja akhir (16-19 tahun), berupa haid tidak teratur, haid yang lebih sedikit dan sangat banyak, nyeri haid serta haid yang lebih sering. Tujuan penelitian untuk mengetahui gambaran pengetahuan dan sikap remaja putri tentang gangguan menstruasi di kelas XII SMAN 02 Pekanbaru. Desain penelitian yang dilakukan adalah kuantitatif dengan metode deskriptif dengan pendekatan cross sectional. Penelitian telah dilaksanakan pada bulan Juli s/d Agustus 2013 di SMAN 02 Pekanbaru kelas VII tahun 2013. Populasi dalam penelitian ini adalah seluruh siswi kelas XII SMAN 02 Pekanbaru tahun 2013. Populasi dalam penelitian ini adalah seluruh Siswi putri kelas XII SMAN 02 Pekanbaru tahun 2013 berjumlah 149 orang dan sampel di ambil secara simple random sampling yang berjunlah 60 orang. Analisa data pengetahuan yang digunakan adalah analisa data univariat dan analisa sikap dengan menggunakan skala likert. Hasil penelitian manunjukkan mayoritas pengetahuan responden cukup berjumlah 43 orang $(71,67 \%)$ dan mayoritas sikap remaja putri tentang gangguan mentruasi di SMAN 02 Pekanbaru negatif sebanyak 33orang (55\%). Diharapkan hasil penelitian ini dapat dijadikan sebagai informasi dimana gangguan menstruasi merupakan hal yang penting diketahui Sehingga remaja putri dapat mengatasi apabila adanya gangguan menstruasi.
\end{abstract}

Kata Kunci: Remaja Putri, Gangguan Menstruasi

\section{A. Pendahuluan}

Kesehatan reproduksi adalah keadaan sejahtera fisik, mental, dan sosial secara utuh, yang tidak semata-mata bebas dari penyakit ataupun kecatatan, dalam semua hal yang berkaitan dengan sistem reproduksi, serta fungsi dan prosesnya (Widiyastuti, 2009). Berdasarkan Defenisi dari Departemen Kesehatan, diketahui bahwa kesehatan 
reproduksi adalah keadaan sehat secara menyeluruh serta reproduksinya. Dengan demikian kesehatan reproduksi bukan hanya kondisi bebas dari penyakit, melainkan bagaimana seseorang dapat memiliki kehidupan seksual yang aman dan memuaskan baik sebelum menikah maupun sesudah menikah (Nugroho, 2011). Kesehatan reproduksi menurut MDG's (Millenium Development Goal's) terdapat pada pilar ke- 5 dan memiliki dua target yaitu Upaya menurunkan angka kematian ibu dan mewujudkan akses kesehatan reproduksi bagi semua (http://dinkes-kabtangerang.go.id /2013/03/643.aspx).

Masalah kesehatan remaja putri pada umumnya sangat bervariatif, salah satunya adalah gangguan saat menstruasi angka kejadian gangguan menstruasi di dunia sangat besar. Rata-rata lebih dari $50 \%$ perempuan di setiap negara mengalami gangguan menstruasi. Di Amerika angka presentasenya sekitar 60\%, diantaranya nyeri haid (dismenorhea) sebesar 27,3\%, amenoera sebesar 12,7\%, menoragia sebesar 13,5\% dan polimenorea sebesar $6,5 \%$ dan di swedia sekitar $72 \%$. Sementara di Indonesia angkanya diperkirakan $55 \%$ perempuan usia produktif mengalami gangguan selama menstruasi (Proverawati dan Misaroh, 2009). Widyastuti (2009), mengatakan setelah lahir kehidupan wanita dapat dibagi dalam beberapa masa yaitu masa bayi, masa kanak-kanak, masa pubertas, masa reproduksi, masa klimakterium dan masa senium. Pembinaan kesehatan reproduksi remaja bertujuan untuk memberikan informasi dan pengetahuan yang berhubungan dengan perilaku hidup sehat bagi remaja, disamping mengatasi masalah yang ada. Pengetahuan yang memadai dan adanya motivasi untuk menjalani masa remaja secara sehat. Diharapkan para remaja mampu memelihara kesehatan dirinya agar dapat memasuki masa kehidupan berkeluarga dengan reproduksi yang sehat.

Umumnya seorang wanita akan mengalami masa pubertas yang ditandai dengan datangnya menstruasi. Menstruasi itu sendiri merupakan pelepasan dinding rahim (endometrium) yang disertai perdarahan dan terjadi tiap bulan, kecuali pada saat kehamilan. Menstruasi yang pertama (menarche) umumnya terjadi pada usia 11 tahun (bisa juga pada usia 8-16 tahun). Menstruasi merupakan pertanda masa reproduktif kehidupan seorang wanita yang dimulai dari menarce sampai menopaus. Hari pertama terjadinya perdarahan dihitung sebagai awal setiap siklus menstruasi yang berkisar antara 21-40 hari. Hanya 10-15\% wanita yang memiliki siklus 28 hari. Pada awalnya, siklus mungkin memang tidak teratur. Jarak antara 2 siklus bisa berlangsung selama 2 bulan, namun dalam 1 bulan bisa saja terjadi 2 siklus. Hal ini normal karena setelah beberapa lama siklus akan menjadi lebih teratur. Setelah beberapa bulan, bisa diketahui pola siklus untuk memperkirakan siklus yang akan datang (Yohanna, dkk, 2011).

Anurogo (2011) sebagian perempuan pada saat haid ada yang mengalami berbagai gangguan haid yang yang cukup berat. Misalnya, ada sebagian yang mengalami kram karena kontraksi otot-otot halus pada rahim, sakit kepala, sakit perut, gelisah berlebihan, merasa letih dan lemas, hidung terasa tersumbat, bahkan selalu ingin menangis. Selain itu ada juga yang mengalami kemarahan tak berujung pangkal, depresi, kondisi ingin makan yang berlebihan, hingga nyeri haid yang luar biasa. Adapula sebagian perempuan yang mengalami kegagalan menstruasi selama waktu tertentu (amenorea). Kondisi ini biasanya disebabkan oleh stress, kehilangan berat badan, olahraga berat yang terus menerus hingga penyakit. Ada pula sebagian perempuan yang mengalami siklus haid secara berlebihan, kondisi ini disebut monoragia, pada kondisi ini, tidak hanya aliran darah yang menjadi sangat deras dan 
banyak, tetapi masa haidnya bisa lebih lama dari masa normal 3-7 hari. Kondisi gangguan haid tersebut akan berpengaruh negatif bagi seorang perempuan dalam menjalani aktifitas sehari-hari, sehingga semua kondisi gangguan haid tersebut haruslah ditangani dengan bijaksana, agar tidak mengganggu kesehatan secara keseluruhan.

Gangguan haid lebih sering terjadi pada remaja akhir (16-19 tahun), berupa haid tidak teratur, haid yang lebih sedikit dan sangat banyak, nyeri haid serta haid yang lebih sering. Remaja siswi dengan usia sekolah yang mengalami gangguan menstruasi akan mempengaruhi pelaksanaan proses belajar mengajar yang dijalaninya (http://www.undp.or.id/pubs.pdf). Jumlah siswa SMA yang ada di Pekanbaru adalah 24.332 jiwa. Jumlah siswa perempuan lebih banyak dibandingkan jumlah siswa lakilaki yaitu sebanyak 13.595 (50,55\%) dari jumlah keseluruhan. SMA 02 Pekanbaru terletak di kecamatan Payung Sekaki. Jumlah siswa 798 jiwa yang terdiri dari 347 jiwa laki-laki dan 451 jiwa perempuan (Dinas Pendidikan kota Pekanbaru, 2012). Peneliti telah melakukan survey awal di tiga SMA di Pekanbaru yaitu SMAN 02 Pekanbaru, SMA Muhamadiyah Pekanbaru, dan SMA Plus Bina Bangsa Pekanbaru. Dari ketiga SMA tersebut masing-masing diambil 10 siswi dan presentasi terbanyak yang tidak mengetahui tentang gangguan saat menstruasi adalah SMAN 02 Pekanbaru. Berdasarkan survey awal yang peneliti lakukan di SMAN 02 Pekanbaru, ternyata kebanyakan dari siswi tersebut kurang memahami tentang gangguan menstruasi. Dimana dari 10 siswi yang didata terdapat 8 siswi yang mengalami gangguan saat menstruasi diantaranya siswi yang mengalami dismenorea terdapat 5 orang dan 3 siswi dengan siklus yang tidak teratur. Dari 10 orang siswi tersebut 7 diantaranya tidak mengetahui bahwa nyeri haid itu merupakan salah satu gangguan menstruasi, 9 siswi tidak mengetahui tentang siklus menstruasi, 10 siswi tidak mengetahui tentang perdarahan yang banyak pada saat menstruasi dan 10 siswi tidak mengetahui tentang terjadinya perdarahan diluar menstruasi.

Artikel ini berisi informasi tentang gambaran pengetahuan dan sikap remaja putri tentang gangguan menstruasi di kelas XII di SMUN 02 Pekanbaru. Tujuan Penelitian ini adalah untuk mengetahui gambaran pengetahuan dan sikap remaja putri tentang gangguan menstruasi di kelas XII SMAN 02 Pekanbaru. Manfaat Penelitian ini Diharapkan sebagai sumber informasi dimana gangguan menstruasi merupakan hal yang penting diketahui. Sehingga remaja putri dapat mengatasi apabila adanya gangguan menstruasi serta memantau program yang berhubungan dengan gangguan menstruasi yang di alami.

\section{B. Metodologi Penelitian}

Desain penelitian yang dilakukan adalah kuantitatif dengan metode deskriptif dengan pendekatan Cross Sectional, yaitu di ukur atau dikumpulkan dalam waktu bersamaan yang bertujuan untuk mengetahui gambaran pengetahuan dan sikap remaja putri tentang gangguan menstruasi pada siswi kelas XII SMA Negeri 02 Pekanbaru. Populasi adalah keseluruhan objek penelitian atau objek yang diteliti (Arikunto, 2010). Populasi pada penelitian ini adalah seluruh siswa putri kelas XII SMAN 02 Pekanbaru tahun 2013 berjumlah 149 orang. Sampel adalah sebagian atau wakil populasi yang diteliti (Arikunto, 2010). Berdasarkan rumus jumlah sampel pada penelitian ini 60 siswi. Sampel dalam penelitian ini adalah semua siswi kelas XII SMAN 02 Pekanbaru yang terdiri dari 7 kelas. Alat ukur yang digunakan dalam penelitian ini yaitu lembar kuesioner untuk mengumpulkan data responden di SMAN 02 Pekanbaru dengan pengetahuan dan sikap remaja putri tentang gangguan pada saat menstruasi. Teknik 
pengumpulan data yang digunakan oleh peneliti yaitu data primer dengan cara pengumpulan data yang dilakukan secara langsung. Analisis data untuk variabel penelitian yang peneliti gunakan adalah analisa data univariat dan ditampilkan dalam bentuk tabel distribusi dan dipresentasikan dari tiap-tiap variabel. Menurut Notoatmodjo (2010) analisa sikap dengan menggunakan skala likert, dimana pertanyaan positif dan pernyataan negatif menggunakan scoring.

\section{Hasil dan Pembahasan}

Hasil penelitian pengetahuan dan sikap remaja putri tentang gangguan menstruasi di SMAN 02 Pekanbaru disajikan berupa tabel distribusi frekuensi. Penelitian yang dilakukan terhadap 60 siswi di SMA N 02 Pekanbaru Waktu penelitian dilaksanakan pada tanggal 26 Juli s/d 16 Agustus 2013, didapat data sebagai berikut:

Tabel 1 Distribusi Frekuensi Siswi Berdasarkan Umur di Kelas XII SMA N 2

Pekanbaru

\begin{tabular}{cccc}
\hline No & Umur & Frekuensi (orang) & Persentase $(\boldsymbol{\%})$ \\
\hline 1 & 17 tahun & 7 & 11,67 \\
2 & 18 tahun & 39 & 65,00 \\
3 & 19 tahun & 14 & 23,33 \\
\hline \multicolumn{2}{c}{ Total } & $\mathbf{6 0}$ & $\mathbf{1 0 0}$ \\
\hline
\end{tabular}

Berdasarkan tabel 1 diketahui bahwa dari 60 siswi mayoritas 18 tahun sebanyak 39 orang $(65,00 \%)$.

\section{Pengetahuan Remaja Putri tentang Gangguan Menstruasi}

Tabel 2 Distribusi Frekuensi Pengetahuan Remaja Putri Tentang Gangguan Menstruasi di Kelas XII SMA N 2 Pekanbaru

\begin{tabular}{clcc}
\hline No & Pengetahuan & Frekuensi (orang) & Persentase $(\%)$ \\
\hline 1 & Baik & 3 & 5,00 \\
2 & Cukup & 43 & 71,67 \\
3 & Kurang & 14 & 23,33 \\
\hline & Total & $\mathbf{6 0}$ & $\mathbf{1 0 0}$
\end{tabular}

Berdasarkan tabel 2 diketahui bahwa dari 60 siswi, mayoritas berpengetahuan cukup terhadap Gangguan menstruasi sebanyak 43 orang $(71,67 \%)$.

\section{Sikap Remaja Putri tentang Gangguan Menstruasi}

Tabel 3 Distribusi Frekuensi Sikap Remaja Putri Tentang Gangguan Menstruasi di Kelas XII SMA N 2 Pekanbaru Tahun 2013

\begin{tabular}{cccc} 
No & Sikap & Frekuensi (orang) & Persentase $(\%)$ \\
\hline 1 & Positif & 29 & 48,33 \\
2 & Negatif & 31 & 51,67 \\
\hline \multicolumn{2}{c}{ Total } & $\mathbf{6 0}$ & $\mathbf{1 0 0}$
\end{tabular}

Berdasarkan tabel 3 dapat diketahui bahwa dari 60 siswi, mayoritas mempunyai sikap negatif terhadap gangguan menstruasi sebanyak 31 orang $(51,67 \%)$.

Berdasarkan hasil penelitian yang telah diuraikan pada bab sebelumnya,maka hasil penelitian tersebut akan dilakukan pembahasan sesuai dengan konsep teori yang 
telah diperoleh dalam beberapa literatur. Adapun hasil pembahasan tersebut akan diuraikan sebagai berikut:

\section{Interpretasi dan Hasil Diskusi}

\section{Data Umum}

Umur. Berdasarkan tabel 1 didapat umur siswi mayoritas adalah 18 tahun sebanyak 39 orang $(65,00 \%)$ yang tergolong pada umur remaja akhir (16-19 tahun). Pada usia ini merupakan masa mulai beralihnya dari masa remaja kedewasa sehingga remaja tersebut akan mengalami banyak masalah yang salah satunya masalah gangguan menstruasi. Gangguan haid lebih sering terjadi pada remaja akhir (16-19 tahun) berupa haid tidak teratur, haid yang lebih sedikit dan sangat banyak, nyeri haid serta haid yang lebih sering. Remaja siswi dengan usia sekolah yang mengalami gangguan menstruasi akan mempengaruhi pelaksanaan proses belajar mengajar yang dijalaninya (http://www.undp.or.id/pubs.pdf).

\section{Data Khusus}

Pengetahuan Remaja Putri Tentang Gangguan Menstruasi. Hasil penelitian yang dilakukan diperoleh pengetahuan tentang gangguan menstruasi diketahui pengetahuan kurang sebanyak 14 orang $(23,33 \%)$, pengetahuan cukup sebanyak 43 orang $(71,67 \%)$ dan pengetahuan baik 3 orang $(5,00 \%)$. Dari data tersebut dapat dilihat sebagian besar responde nmemiliki pengetahuan yang cukup terhadap gangguan menstruasi. Apabila dihubungkan dengan umur, berdasarkan penelitian yang telah dilakukan didapat mayoritas umur 18 tahun dimana sesuai dengan yang dikatakan Yudistira (2010), umur 17-20 tahun merupakan umur yang baik dalam proses pengetahuan dan belajar secara bertahap, pada masa ini seseorang sudah mulai memiliki cara berfikir yang baik, Karena pada usia ini pola fikir seseorang menujuk kearah lebih matang (kedewasaan). Sehingga diharapkan dengan adanya pertambahan umur dan pengalaman responden dapat mempunyai pengetahuan yang lebih baik. Sesuai dengan pernyataan Kiswanto (2009), pendidikan tidak selamanya dapat mempengaruhi pengetahuan seseorang, melainkan pengetahuan lebih dominan dipengaruhi oleh faktor pengalaman hidup seseorang. Dengan kata lain, meskipun seseorang tidak berpendidikan namun karena pengalamannya banyak maka pengetahuan seseorang tersebut akan dapat lebih baik dibandingkan dengan orang berpendidikan tinggi. Menurut Notoatmodjo (2010) Pengetahuan adalah keseluruhan pemikiran, gagasan, ide konsep dan pemahaman yang dimiliki manusia. Pengetahuan mencakup penalaran dan pemahaman manusia tentang segala sesuatu yang mencakup praktek atau kemampuan dalam memecahkan persoalan hidup yang belum dibakukan secara sistematis dan metodis. Sedangkan menurut Budiman (2013), Pengetahuan adalah sebagai suatu pembentukan yang terus menerus oleh sesorang yang setiap saat mengalami reorganisasi karena adanya pemahamanpemahaman baru.

Sikap Remaja Putri Tentang Gangguan Menstruasi. Berdasarkan tabel 3 dapat dilihat bahwa sikap remaja putri tentang gangguan menstruasi di SMA Negeri 02 Pekanbaru adalah negatif sebanyak 31 orang $(51,67 \%)$. Dari data tersebut dapat dilihat lebih banyak responden yang memiliki sikap cukup dalam menghadapi gangguan menstruasi dan diharapkan dapat lebih baik lagi. Dari hasil penelitian didapat bahwa sebagian besar responden memiliki pengetahuan yang cukup dan hanya 5,00\% yang memiliki pengetahuan baik, hal ini berhubungan dengan pernyataan Arif (2009), mengatakan seseorang dengan pengetahuan yang cukup atau kurang, bisa berdampak pada sikap negatif terhadap dirinya. Karenas eseorang yang memiliki pengetahuan cukup kurang bisa menyikapi hal yang dialaminya. Tetapi sebaliknya orang yang memiliki pengetahuan yang baik akan berdampak pada sikap yang positif pula. Hasil

E-ISSN: 2657-0300 Lembaga Penelitian dan Penerbitan Hasil Penelitian Ensiklopedia $\quad 237$


penelitian ini sesuai dengan hasil penelitian yang dilakukan Zaini (2010) tentang gambaran Pengetahuan dan Sikap Remaja Putri tentang Gangguan Menstruasi di SMA N 01 Surakarta, diperoleh hasil responden sebanyak 32 (65,0\%) siswi yang memiliki pengetahuan cukup, dan $29(62,1 \%)$ siswi yang memiliki sikap negatif. Ini menunjukkan pengetahuan dan sikap remaja putri tentang gangguan menstruasi di SMA N 01 Surakarta adalah cukup, dan diharapkan adanya informasi dan pengetahuan agar siswi memiliki pengetahuan yang lebih baik lagi.

Menurut Notoatmodjo (2010), pengetahuan dan sikap saling mempengaruhi satu sama lain. Sikap dapat berubah-ubah, karena sikap itu dapat dipelajari orang atau sebaliknya, bila terdapat keadaan-keadaan tertentu yang mempermudah berubahnya sikap. Berarti sikap yang negatif bisa berubah menjadi positif, jika didukung oleh fasilitas atau faktor pendukung lainnya, dan sebaliknya. Sikap merupakan reaksi tertutup terhadap suatu stimulasi atau objek. Manifestasi sikap itu tidak langsung dapat dilihat, tetapi hanya dapat ditafsirkan terlebih dahulu dari perilaku yang tertutup. Sikap itu merupakan kesiapan atau keadaan untuk bertindak atau bukan merupakan pelaksana motif tertentu. Sikap belum tentu merupakan suatu tindakan aktivitas, akan tetapi predisposisi tindakan perilaku. Berdasarkan penelitian yang telah dilakukan, peneliti menyatakan sebagian besar responden mayoritas berpengetahuan cukup dan lebih banyak responden bersikap negatif, hal tersebut dapat diambil kesimpulan dengan kurangnya pengetahuan yang dimiliki responden dapat mempengaruhi sikap yang negatif.

Keterbatasan Penelitian. Dalam penelitian ini peneliti merasa adanya keterbatasan dalam melaksanakan penelitian, adapun keterbatasan yang peneliti hadapi adalah sebagai berikut, dalam penelitian ini, peneliti hanya menggunakan desain penelitian deskriptif dan kuantitatif, jadi hanya menggambarkan hasil pengetahuan dan sikap siswi saja dan tidak dilanjutkan penelitian lebih dalam. Ada beberapa responden yang tidak menganalisa dan menjawab kuesioner sesuai kemampuan atau pengetahuan sendiri, sehingga peneliti harus terus $\mathrm{m}$

\section{Penutup}

Berdasarkan hasil penelitian yang telah dilakukan dan telah disajikan pembahasan, maka selanjutnya akan disajikan kesimpulan dan saran atas penelitian terhadap pengetahuan dan sikap remaja putri tentang gangguan menstruasi di kelas XII SMA N 02 Pekanbaru. Pengetahuan remaja putri tentang gangguan menstruasi sebagian besar dalam kategori cukup yaitu sebesar 43 orang $(71,67 \%)$. Sikap remaja putri tentang gangguan menstruasi lebih banyak bersikap negative sebanyak 31 orang $(51,67 \%)$.

\section{Daftar Pustaka}

Arikunto, S. (2010). Prosedur Penelitian Suatu Pendekatan Praktik. Jakarta: Rineka Cipta

Budiman. (2013). Kapita Selekta Kuesioner dan Sikap Dalam Penelitian Kesehatan. Jakarta: Salemba Medika

Dinkes Kabupaten Tangerang. (2013). MDG's (http://dinkes-kabtangerang.go.id /2013/03/643.aspx) di akses tanggal 27 April 2013

Dinpen, (2012). Profil Dinas Pendidikan Kota Pekanbaru. 
Hidayat, A. (2011). Metode Penelitian Kebidanan dan Teknik Analisis Data. Jakarta: Salemba Medika

Kusmiran. (2011). Kesehatan Reproduksi Remaja dan Wanita. Jakarta: Salemba Medika

Laila. (2011). Buku Pintar Menstruasi. Yogyakarta: Buku Biru

Nasir, dkk. (2011). Metodologi Penelitian Kesehatan. Yogyakarta: Nuha Medika

Notoatmodjo, S. (2010). Metodologi Penelitian Kesehatan. Jakarta: Rineka Cipta

Nugroho. (2011). Catatan Kuliah Ginekologi dan Obstetri. Yogyakarta: Nuha Medika

Olaf. (2009). Prevalensi Gangguan Menstruasi dan Faktor-faktor yang Berhubungan pada Siswi SMU Kelas XII di Kecamatan Pulo Gadung Jakarta Timur

Proverawati dan Misaroh. (2009). Menarche Menstruasi Pertama Penuh Makna. Yogyakarta: Mulia Medika

Rianda, A. S. (2011). Gambaran Gangguan Haid Pada Mahasiswi Fakultas Kedokteran Universitas Sumatra Utara Tingkat I Angkatan 2010

Sarwono. (2011). Ilmu Kebidanan. Jakarta: PT. Bina Pustaka

Setiawan dan Saryono. (2011). Metodologi Penelitian Kebidanan D-III, D-IV, S1 dan S2. Yogyakarta: Mulia Medika

Sibagariang. (2010). Kesehatan Reproduksi Wanita. Jakarta: Trans Info Media

Widyastuti. (2009). Kesehatan Reproduksi. Yogyakarta: Fitramaya

Yeti. (2005). Gambaran Siswa Yang Mengalami Disminorea Pada Remaja Kelas VII SLTP 12 Semarang

Yohana, dkk. (2011). Kehamilan dan Persalinan. Jakarta: Garda Media 